\title{
CONSTRUÇÃO E APLICAÇÃO DE BIOSSENSORES USANDO DIFERENTES PROCEDIMENTOS DE IMOBILIZAÇÃO DA PEROXIDASE DE VEGETAL EM MATRIZ DE QUITOSANA
}

\author{
Inês Rosane Welter Zwirtes de Oliveira e Iolanda Cruz Vieira* \\ Departamento de Química, Universidade Federal de Santa Catarina, CP 476, 88040-900 Florianópolis-SC
}

Recebido em 16/5/05; aceito em 3/11/05; publicado na web em 31/3/06

\begin{abstract}
CONSTRUCTION AND ANALYTICAL APPLICATIONS OF BIOSENSORS USING DIFFERENT IMMOBILIZATION PROCEDURES OF VEGETABLE PEROXIDASE ON CHITOSAN MATRIX. Biosensors were developed by immobilization of gilo (Solanum gilo) enzymatic extract on chitosan biopolymers using three different procedures: glutaraldehyde, carbodiimide/ glutaraldehyde and epichlorohydrin/glutaraldehyde. The best biosensor performance was obtained after the immobilization of peroxidase on chitosan with epichlorohydrin/glutaraldehyde. Linear analytical curves for hydroquinone concentrations from $2.5 \times 10^{-4}$ to $4.5 \times 10^{-3} \mathrm{~mol} \mathrm{~L}^{-1}$ with a detection limit of $2.0 \times 10^{-6} \mathrm{~mol} \mathrm{~L}^{-1}$ and recovery of hydroquinone ranging from 95.1 to $105 \%$ were obtained. The relative standard deviation was $<1.0 \%$ for a solution of $3.0 \times 10^{-4} \mathrm{~mol} \mathrm{~L}^{-1}$ hydroquinone and $2.0 \times 10^{-3} \mathrm{~mol} \mathrm{~L}^{-1}$ hydrogen peroxide in $0.1 \mathrm{~mol} \mathrm{~L}^{-1}$ phosphate buffer solution at $\mathrm{pH} 7.0(\mathrm{n}=8)$. The lifetime of this biosensor was 6 months (at least 300 determinations).
\end{abstract}

Keywords: chitosan; biosensor; peroxidase.

\section{INTRODUÇÃO}

Desde o desenvolvimento do primeiro biossensor, em 1962, diversos outros foram construídos utilizando diferentes enzimas e procedimentos de imobilização. Apresentam características importantes, tais como seletividade, baixo custo e facilidade na construção, potencial para miniaturização, resposta rápida, potencial de automação e construção de equipamentos simples e portáteis ${ }^{1}$. Um biossensor pode ser definido como um sensor que combina a alta seletividade de um elemento biológico sensível ao analito de interesse, ligado a um transdutor que converte o sinal biológico em sinal elétrico proporcional à concentração do analito ${ }^{1-8}$.

O desenvolvimento de técnicas de imobilização tem sido importante por proporcionar a reutilização das enzimas, aumentar a estabilidade, reduzir custos e aumentar, em alguns casos, a atividade enzimática. Esses fatores dependem principalmente da escolha apropriada do suporte e dos reagentes utilizados no processo de imobilização $0^{2-10}$. Os métodos de imobilizações podem ser divididos nas seguintes categorias: oclusão em gel, microencapsulação, adsorção física, ligação química covalente e ligação química covalente cruzada. O método da ligação química covalente cruzada é muito utilizado e baseia-se na formação de ligações covalentes entre as moléculas da enzima e/ou do suporte inerte com reagentes funcionais. O glutaraldeído, em função de suas propriedades bifuncionais, tem sido um dos reagentes mais empregado na imobilização de enzimas, devido à formação de ligações covalentes entre a enzima e o suporte sólido, conferindo à enzima maior estabilidade. No entanto, há relatos na literatura da utilização de vários reagentes no processo de imobilização, entre eles, diazobenzidina, carbodiimida, ácido bisdiazobenzidínico, triclorotriazina ${ }^{2-10}$.

O eletrodo de pasta de carbono proposto por Adams, em 1958, é uma composição de pó de grafite e de um líquido orgânico imiscível em solução aquosa ${ }^{11}$. Esse eletrodo oferece versatilidade, baixo custo, modificação conveniente e facilidade de renova-

*e-mail: iolanda@qmc.ufsc.br ção da superfície. Devido a essas propriedades é muito utilizado e uma das principais vantagens da pasta de carbono na construção de eletrodos é que possibilita a modificação interna do material eletródico, diferentemente do que ocorre com os eletrodos convencionais, em que a modificação ocorre apenas na superfície ${ }^{12-14} . \mathrm{O}$ desenvolvimento dos eletrodos de pasta de carbono modificados com enzimas é amplamente divulgado na literatura ${ }^{3,5,9}$; tais eletrodos possuem a vantagem de diminuir o limite de detecção do analito de interesse e aumentar a seletividade das determinações ${ }^{2,3,5,9}$.

A quitina, $\beta(1-4)$-2-acetamido-2-deoxi-D-glicose, é o segundo polissacarídeo natural mais abundante encontrado na natureza e está presente em uma variedade de animais marinhos (caranguejo, camarão, lagosta), insetos, fungos e leveduras. A quitosana, $\beta(1-$ 4)-2-amino-2-deoxi-D-glicose, é o principal derivado da quitina, obtida a partir da desacetilação por processo de hidrólise básica ${ }^{15-17}$. A quitosana é considerada um suporte ideal para imobilização de enzimas, devido ao grande percentual de grupos amino e hidroxila disponíveis em sua estrutura química. Possui facilidade para formação de gel, é hidrofílica, biodegradável, biocompatível e antibactericida. Além disso, é economicamente viável, e bastante empregada na medicina, em produtos farmacêuticos, na agricultura, em biotecnologia, na indústria de cosméticos e de alimentos e, também, como adsorvente na remoção de corantes e no tratamento de efluentes industriais ${ }^{15-17}$.

O principal problema durante o processo de imobilização de uma enzima pode ser a perda parcial ou total da atividade, que pode ser atribuída a diversos fatores, como propriedades da própria enzima, do suporte, dos reagentes utilizados e das condições experimentais. Delanoyet al. ${ }^{18}$ estudaram a estabilidade e a atividade da lacase imobilizada em quitosana. Comprovaram que a enzima apresentou estabilidade superior quando comparada com a lacaselivre. A quitosana, quimicamente modificada, tem sido empregada tanto na forma de microesferas, quanto na de filmes, ou de pó, ou de membranas, como adsorvente de metais ${ }^{10,15-17}$, na imobilização de diversas enzimas (creatinase deaminase ${ }^{19}$, galactose oxidase ${ }^{20}$, glutamato oxidase ${ }^{20}$, glicose oxidase ${ }^{21}$, peroxidase ${ }^{22-24}$, lactato oxidase $^{25}$, sulfito oxidase ${ }^{26,27}$ ) e na construção de biossensores ${ }^{19-27}$. 
A enzima peroxidase pode ser encontrada em vários vegetais e catalisa a oxidação de mono, di e polifenóis em presença de peróxido de hidrogênio ${ }^{28,29}$. O uso de extrato bruto de vegetais, como fonte de enzimas para construção de biossensores, tem se tornado freqüente, devido à simplicidade e facilidade de obtenção da enzima, ao baixo custo do processo, à estabilidade e ao tempo de vida superior àqueles métodos que utilizam enzimas purificadas. Diferentes vegetais têm sido investigados e utilizados na construção de biossensores $^{9,24,30-35}$. Recentemente, extrato bruto de gengibre (Zingiber officinales Rosc.) foi obtido como fonte da enzima peroxidase e utilizado para construção e aplicação de um biossensor ${ }^{24}$.

A hidroquinona, obtida pela primeira vez em 1820 por Pelletier e Caventou ${ }^{36}$, é utilizada em processos biológicos, industriais e em cosméticos. No processo de revelação fotográfica é utilizada como redutor, onde é facilmente oxidada a quinona ${ }^{36}$. Diversos procedimentos são descritos na literatura para determinação de hidroquinona em revelador fotográfico e creme dermatológico, entre eles, os cromatográficos ${ }^{36-38}$, o de eletrodo de pasta de carbono ${ }^{39}$ e os biossensores ${ }^{24,30,35}$.

No presente trabalho, a enzima peroxidase obtida do vegetal jiló (Solanum gilo) foi imobilizada em matriz de quitosana, previamente reticulada, e ativada por três procedimentos diferentes: (I) grupos amino da quitosana foram reticulados com glutaraldeído; (II) grupos amino da quitosana foram reticulados com glutaraldeído e grupos hidroxila ativados com carbodiimida; (III) grupos amino e hidroxila da quitosana foram reticulados com glutaraldeído e epicloridrina, respectivamente. Após as imobilizações, os biossensores foram construídos e parâmetros, tais como $\mathrm{pH}$, concentração da enzima, freqüência, amplitude de potencial e Epc (potencial de pico catódico), foram investigados. As técnicas de voltametria cíclica e voltametria de onda quadrada foram utilizadas para otimização e comparação dos biossensores que foram usados para a determinação de hidroquinona em águas obtidas nos processos de revelação fotográfica e de raios-X.

\section{PARTE EXPERIMENTAL}

\section{Equipamentos e eletrodos}

O extrato enzimático foi obtido homogeneizando-se o vegetal selecionado em um triturador Black \& Decker modelo IB900. Efetuou-se a centrifugação do material biológico em uma centrífuga Hitachi modelo Himac CR 20B2.

As medidas espectrofotométricas, para determinação da atividade e proteína total da enzima peroxidase, foram obtidas empregando um espectrofotômetro Femto modelo 434, utilizando uma cubeta de quartzo de $1,00 \mathrm{~cm}$ de caminho ótico.

Os espectros na região do infravermelho da quitosana foram obtidos usando um espectrofotômetro FT Perkin Elmer, modelo 16 PC. As titulações condutométricas, empregando um condutivímetro da Micronal, modelo B330 e um titulador automático Schott Geräte, modelo T 80/20.

Os eletrodos de trabalho utilizados foram os biossensores, construídos a partir dos três procedimentos de imobilização da peroxidase na matriz de quitosana. O contra-eletrodo usado foi de platina com área de $0,5 \times 1,0 \mathrm{~cm}$ e o de referência de prata-cloreto de prata $(\mathrm{Ag} / \mathrm{AgCl})$, com solução interna de $\mathrm{KCl} 3,0 \mathrm{~mol} \mathrm{~L}^{-1}$, separada da solução de trabalho por uma placa porosa ultra fina de vycor.

As medidas de voltametria cíclica e voltametria de onda quadrada foram obtidas utilizando-se um potenciostato/galvanostato PAR, modelo 273 EG\&G, usando uma célula de vidro, sem compartimento divisório, com capacidade de $15 \mathrm{~mL}$, com tampa de
PVC com orifícios circulares para encaixe dos eletrodos e adição das soluções.

\section{Reagentes e soluções}

Reagentes de grau analítico foram obtidos da Sigma e usados para preparar as soluções tampão e de referência.

Quitosana com aproximadamente $80 \%$ de desacetilação foi usada como suporte para imobilizar a enzima peroxidase. Foram utilizados glutaraldeído e epicloridrina, para reticular os grupos amino da quitosana e a carbodiimida, para ativar os grupos hidroxila.

Soluções de guaiacol, peróxido de hidrogênio e hidroquinon foram preparadas diariamente em solução tampão fosfato $0,1 \mathrm{~mol}$ $\mathrm{L}^{-1}, \mathrm{pH} 7,0$.

Para a construção dos biossensores foram utilizados pó de grafite, Acheson-38, Fischer, e óleo mineral, nujol, Aldrich.

Foram determinados os teores de hidroquinona em amostras de águas do processo de revelação fotográfico e de raios-X, obtidas no comércio e no Hospital Universitário, respectivamente, da cidade de Florianópolis, SC.

\section{Obtenção e quantificação da peroxidase do tecido vegetal}

O vegetal jiló foi adquirido em supermercados de Florianópolis, e o extrato bruto, fonte enzimática, obtido conforme descrito na literatura ${ }^{24,35}$. Após lavagem e secagem, $25 \mathrm{~g}$ de jiló descascado foram picadas e homogeneizadas em liquidificador, com $100 \mathrm{~mL}$ de solução tampão fosfato $0,1 \mathrm{~mol} \mathrm{~L}^{-1}, \mathrm{pH} 7,0$. Em seguida, foi filtrado em gazes e centrifugado a $25.000 x g, 18.000 \mathrm{rpm}$, durante 5 min, a $4{ }^{\circ} \mathrm{C}$. A solução sobrenadante foi dividida em diversas alíquotas, armazenadas em refrigerador a $4{ }^{\circ} \mathrm{C}$, e usadas como fonte da enzima peroxidase para construção dos biossensores.

A atividade enzimática - unidades $\mathrm{mL}^{-1}$ - definida como a quantidade de enzima que causa o aumento de 0,001 unidades de absorbância por min, foi determinada medindo-se a absorbância do tetraguaiacol formado na reação enzimática com solução de guaiacol $0,05 \mathrm{~mol} \mathrm{~L}^{-1}$ e peróxido de hidrogênio $10,0 \mathrm{mmol} \mathrm{L}^{-1}$, em tampão fosfato $0,1 \mathrm{~mol} \mathrm{~L}^{-1}, \mathrm{pH} 7,0$, em $470 \mathrm{~nm}^{24,35}$.

O teor de proteína total do extrato enzimático foi determinado pelo método do biureto ${ }^{40}$, empregando-se albumina de soro bovino como padrão.

\section{Grau de desacetilação e tempo de reticulação da quitosana com glutaraldeído}

O grau de desacetilação, porcentagem de grupo amino da quitosana, foi determinado por titulação condutométrica e espectroscopia de infravermelho ${ }^{41,42}$. Uma amostra de $0,2 \mathrm{~g}$ de quitosana foi dissolvida em $20 \mathrm{~mL}$ de solução de ácido clorídrico $0,1 \mathrm{~mol} \mathrm{~L}^{-1} \mathrm{e}$ titulada com solução de hidróxido de sódio $0,1 \mathrm{~mol} \mathrm{~L}^{-1}$. O espectro de infravermelho do pó de quitosana foi obtido na região de 4000 a $400 \mathrm{~cm}^{-1}$, utilizando como suporte partilha de $\mathrm{KBr}^{41,42}$.

$\mathrm{O}$ estudo do tempo de reação para reticulação da quitosana com glutaraldeído foi de $10 \mathrm{~min}$ a $24 \mathrm{~h}$. Foram preparadas seis amostras contendo $2,0 \mathrm{~g}$ de pó de quitosana e $60 \mathrm{~mL}$ de solução de glutaraldeído 2,5\% (v/v). As amostras foram, respectivamente, agitadas por 10, $30 \mathrm{~min}, 1,5,10$ e $24 \mathrm{~h}$, a $25^{\circ} \mathrm{C}$. Após os diferentes tempos de reação e agitação, foram centrifugadas, a quitosana lavada com água destilada para remover o excesso de glutaraldeído e posteriormente, seca com acetona. Subseqüentemente, alíquota de $20 \mathrm{~mL}$ de solução de ácido clorídrico $0,1 \mathrm{~mol} \mathrm{~L}^{-1}$ foi adicionada a $0,2 \mathrm{~g}$ de pó de quitosana reticulada proveniente dos diferentes tempos de reação, agitada por $30 \mathrm{~min}$, a $25^{\circ} \mathrm{C}$. Em seguida, cada uma 
dessas soluções foi titulada condutometricamente com hidróxido de sódio $0,1 \mathrm{~mol} \mathrm{~L}^{-1}$ e determinada a porcentagem de grupos amino livres na quitosana. A técnica de espectroscopia de infravermelho também foi utilizada para determinar e comparar o grau de desacetilação da quitosana ${ }^{41,42}$.

\section{Imobilização da peroxidase}

Foram desenvolvidos três procedimentos diferentes para imobilização da enzima peroxidase na matriz de quitosana (QTS). Após a imobilização, esses materiais foram utilizados na construção dos biossensores.

Reticulação dos grupos amino da quitosana com glutaraldeído.

Reticulou-se $1,0 \mathrm{~g}$ de quitosana com $30 \mathrm{~mL}$ de solução de glutaraldeído 2,5\% (v/v), em tampão fosfato $0,1 \mathrm{~mol} \mathrm{~L}^{-1}, \mathrm{pH} 7,0$, por 30 min sob agitação. Em seguida, a quitosana foi lavada com solução tampão fosfato $0,1 \mathrm{~mol} \mathrm{~L}^{-1}, \mathrm{pH} 7,0$, para eliminar o excesso de glutaraldeído, seca com acetona e armazenada a $25{ }^{\circ} \mathrm{C}$.

Reticulação dos grupos amino e ativação das hidroxilas com glutaraldeído-carbodiimida

A quitosana foi inicialmente reticulada com glutaraldeído, como descrito no procedimento anterior. Alíquota de $30 \mathrm{~mL}$ de solução de carbodiimida $3,7 \times 10^{-4}$ mol L-1, preparada em solução tampão $0,1 \mathrm{~mol} \mathrm{~L}^{-1}, \mathrm{pH} 7,0$, foi adicionada à quitosana pulverizada e, após 30 min, lavou-se com solução tampão de fosfato, $\mathrm{pH} 7,0$, para remover o excesso de carbodiimida.

Reticulação dos grupos amino e hidroxila da quitosana com glutaraldeído e epicloridrina

À quitosana, previamente reticulada com glutaraldeído, foram adicionados $25 \mathrm{~mL}$ de solução de epicloridrina $6,2 \times 10^{-3} \mathrm{~mol} \mathrm{~L}^{-1}$, em solução tampão $0,1 \mathrm{~mol} \mathrm{~L}^{-1}, \mathrm{pH} 7,0$. Durante $1 \mathrm{~h}$, a $50^{\circ} \mathrm{C}$, essa solução foi mantida sob agitação e, em seguida, foram adicionados 7,0 mL de solução de $\mathrm{NaOH} 0,1 \mathrm{~mol} \mathrm{~L}^{-1}$. Após $2 \mathrm{~h}$ em ebulição, a quitosana reticulada com glutaraldeído e epicloridrina foi lavada com água, solução de $\mathrm{NaOH} 0,1 \mathrm{~mol} \mathrm{~L}^{-1}$, solução de $\mathrm{HCl} 0,1 \mathrm{~mol}$ $\mathrm{L}^{-1}$ e, finalmente, com solução tampão fosfato $0,1 \mathrm{~mol} \mathrm{~L}^{-1}, \mathrm{pH} 7,0$, para eliminar o excesso dos reagentes adicionados.

A quitosana, em pó, reticulada e ativada pelos três procedimentos descritos, foi utilizada como suporte sólido para imobilização da peroxidase. Foram adicionadas alíquotas de 35 a $400 \mathrm{~mL}$ do extrato enzimático (260 a 3000 unidades de peroxidase $\mathrm{mg}^{-1}$ de proteína) sobre $0,1 \mathrm{~g}$ de quitosana. Após $1 \mathrm{~h}$ sob agitação, esse material foi lavado com tampão fosfato $0,1 \mathrm{~mol} \mathrm{~L}^{-1}, \mathrm{pH} 7,0$, para retirar o excesso de enzima, seco e armazenado à temperatura ambiente.

\section{Construção dos biossensores}

Três tipos de biossensores contendo peroxidase de jiló incorporada em matriz de quitosana com grupos amino e hidroxila ativados e reticulados, segundo procedimentos descritos anteriormente, foram construídos.

Inicialmente, foram homogeneizados $375 \mathrm{mg}$ de pó de grafite, $75 \%(\mathrm{~m} / \mathrm{m})$, e $50 \mathrm{mg}$ de quitosana, $10 \%(\mathrm{~m} / \mathrm{m})$, contendo em sua matriz 1500 unidades de peroxidase $\mathrm{mg}^{-1}$ de proteína, durante 20 min. Em seguida, foram adicionados $75 \mathrm{mg}$ de Nujol, $15 \%(\mathrm{~m} / \mathrm{m})$, homogeneizados por mais $20 \mathrm{~min}$, embutidos em seringas de 1 $\mathrm{mL}$. Finalmente, um fio de cobre $(0,4 \times 11,0 \mathrm{~cm})$ foi inserido para obtenção do contato elétrico e usado como eletrodo de trabalho.

\section{Medidas eletroanalíticas e aplicação dos biossensores}

As medidas voltamétricas foram realizadas em célula de vidro contendo $10 \mathrm{~mL}$ de solução fosfato $0,1 \mathrm{~mol} \mathrm{~L}^{-1}, \mathrm{pH} 7,0$, em peróxido de hidrogênio $2,0 \times 10^{-3} \mathrm{~mol} \mathrm{~L}^{-1}$. As medidas de voltametria cíclica foram realizadas em intervalo de potencial de $+0,45 \mathrm{a}-0,45 \mathrm{~V} v \mathrm{~s}$ $\mathrm{Ag} / \mathrm{AgCl}\left(\mathrm{KCl} \mathrm{3,0} \mathrm{mol} \mathrm{L}^{-1}\right)$, com velocidade de varredura de 100 $\mathrm{mV} \mathrm{s}^{-1}$. As medidas de voltametria de onda quadrada foram feitas em uma faixa de potencial de $+0,3$ a - 0,6 V, amplitude de potencial de 10 a $200 \mathrm{mV}$ e freqüência de 50 a $300 \mathrm{~Hz}$, utilizando solução de hidroquinona.

Os biossensores construídos foram utilizados na determinação de hidroquinona em águas obtidas nos processos de revelação fotográfica e raios-X. Alíquota de $0,10 \mathrm{~mL}$ da amostra foi transferida para a célula contendo $10 \mathrm{~mL}$ de solução tampão fosfato $0,1 \mathrm{~mol} \mathrm{~L}^{-1}$, pH 7,0, peróxido de hidrogênio $2,0 \times 10^{-3} \mathrm{~mol} \mathrm{~L}^{-1}$; o teor de hidroquinona foi determinado pelo método de adição múltipla de padrão. O sinal analítico foi obtido utilizando a técnica de voltametria de onda quadrada em uma faixa de potencial de $+0,3 \mathrm{a}-0,6 \mathrm{~V}$, amplitude de potencial de $100 \mathrm{mV}$ e freqüência de $100 \mathrm{~Hz}$.

Como método comparativo para determinação de hidroquinona nas amostras, foi realizada a titulação redox, utilizando solução de $\mathrm{Ce}^{4+} 0,05 \mathrm{~mol} \mathrm{~L}^{-1}$ como titulante ${ }^{24}$.

\section{RESULTADOS E DISCUSSÃO}

\section{Grau de desacetilação e tempo de reticulação da quitosana com glutaraldeído}

O grau de desacetilação (GD) é uma das principais propriedades que diferencia a quitosana da quitina. $\mathrm{O}$ reconhecimento do GD é essencial quando se estuda a relação entre estrutura-propriedade $^{41,42}$.

Existem vários métodos para determinação do $\mathrm{GD}^{41,42}$. O ideal é que esses métodos sejam simples, eficientes e rápidos. Considerando essas características, a condutometria e a espectroscopia de infravermelho ${ }^{41,42}$ foram utilizadas para quantificação do GD da quitosana. Uma porcentagem de grupos amino livres de 80 e $82 \%$ foi obtida usando a titulação condutométrica e infravermelho, respectivamente.

A reação entre a quitosana e o glutaraldeído, para obtenção da reticulação, foi investigada no período de $10 \mathrm{~min}$ a 24 h. O máximo de reticulação, $100 \%$, foi obtido em solução de glutaraldeído 2,5\% (v/v) a partir de 10 min de reação. Para evitar eventuais erros e garantir a total reticulação da quitosana, selecionou-se o tempo de reticulação de $30 \mathrm{~min}$, para desenvolvimento deste trabalho.

\section{Imobilização da peroxidase na matriz da quitosana}

A enzima peroxidase é encontrada em diversas espécies do reino vegetal e, comercialmente é isolada da raiz forte (Armoracia rusticana), com a denominação de peroxidase de raiz forte (HRP Horseradish peroxidase $)^{1,28,29}$. No Brasil, uma variedade de vegetais, como a batata-salsa (Arracacia xanthorrhiza bancroft), mandioca (Manihot utilissima), gengibre (Zingiber officinales Rosc.), goiaba (Psidium guaiava), abacaxi (Ananas comosus), acelga (Beta vulgaris variedad cycla), fruta-de-conde (Ananas squamosa), foram caracterizadas como fonte da enzima peroxidase ${ }^{24}$. No entanto, neste trabalho foi utilizado o extrato bruto de jiló (Solanum gilo), como fonte da enzima peroxidase, porque possui alta atividade catalítica quando comparado com outros vegetais estudados ${ }^{24}$.

A quitosana, devido ao grande percentual de grupos amino $\left(\mathrm{NH}_{2}\right)$ disponíveis, permite realizar com eficiência a imobilização de 
enzima $^{10}$. No entanto, verifica-se, ainda, a presença de grupos acetamida, uma vez que o percentual de desacetilação encontrado foi de $80 \%$.

O glutaraldeído foi utilizado como agente reticulante, pois possui propriedades bifuncionais que ativam os grupos amino. A Figura 1 ilustra uma sugestão da reação obtida entre quitosana, glutaraldeído e peroxidase. $\mathrm{O}$ glutaraldeído reage com os grupos $\mathrm{NH}_{2}$ da quitosana formando uma rede polimérica, na qual a enzima peroxidase está aprisionada entre os interstícios formados. Além disso, existe a possibilidade da enzima encontrar-se ligada em uma das extremidades do glutaraldeído.

$$
\begin{aligned}
& {\left[\mathrm{OH}_{\mathrm{NH}_{2}}{ }_{\mathrm{OH}}^{\mathrm{OH}}\right]_{\mathrm{n}}+\mathrm{HOC}_{\left(\mathrm{CH}_{2}\right)_{3} \mathrm{COH}}+\frac{\mathrm{NH}_{2}}{\text { peroxidase }}} \\
& \begin{array}{lll}
\text { (a) Quitosana (QTS) } & \text { (b) Glutaraldeido } & \text { (c) Enzima }
\end{array}
\end{aligned}
$$

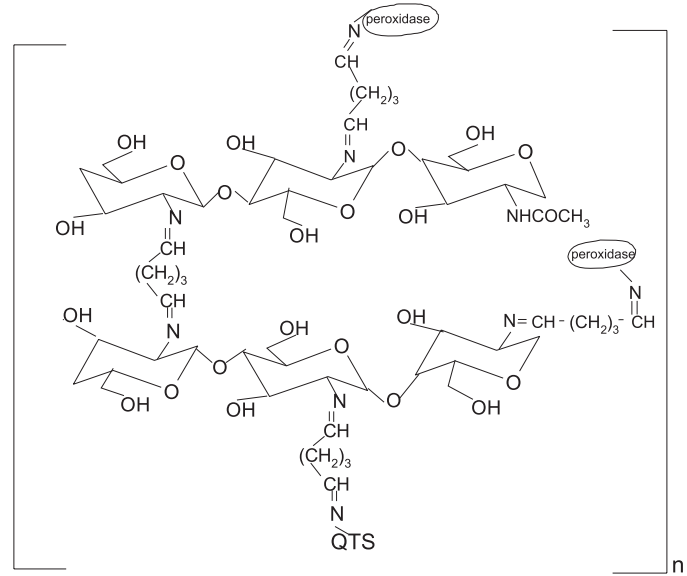

(e)

Figura 1. Esquema da reação entre quitosana (QTS), glutaraldeído e enzima peroxidase (procedimento I)

Para obtenção de maior eficiência na imobilização da enzima na matriz da quitosana e, conseqüentemente, maior resposta analítica do biossensor, foi utilizada neste trabalho a carbodiimida como reagente ativador, reagindo preferencialmente com os grupos carbonila da quitosana (II). Inicialmente, os grupos amino da quitosana são reticulados com glutaraldeído, os grupos hidroxila ativados com carbodiimida e, posteriormente, ocorre a reação com a peroxidase (Figura 2)

O biossensor (III) foi construído com o objetivo de comparar a eficiência da imobilização da enzima utilizando um segundo agente reticulante. A epicloridrina pode ser usada para a insolubilização (reticulação) da quitosana através da formação de uma rede tridimensional polimérica. Na reação com a matriz da quitosana, a epicloridrina reage somente com os grupos hidroxila sob condições alcalinas, ocorrendo abertura do anel epóxido. A Figura 3 mostra o esquema da reação entre quitosana com glutaraldeído, epicloridrina e a peroxidase.

Também foi construído um biossensor contendo extrato enzimático de jiló adsorvido em quitosana e comparado com os demais desenvolvidos nesse trabalho. Esse biossensor apresentou menor desempenho (dados não mostrados).

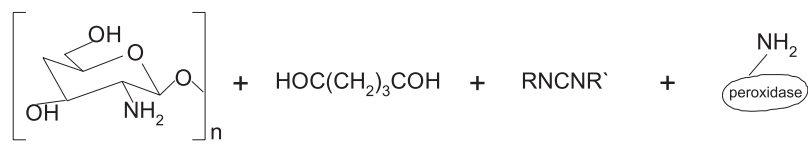

$\begin{array}{llll}\text { (a) Quitosana (QTS) } & \text { (b) Glutaraldeído } & \text { (c) Carbodiimida } & \text { (d) Enzima }\end{array}$

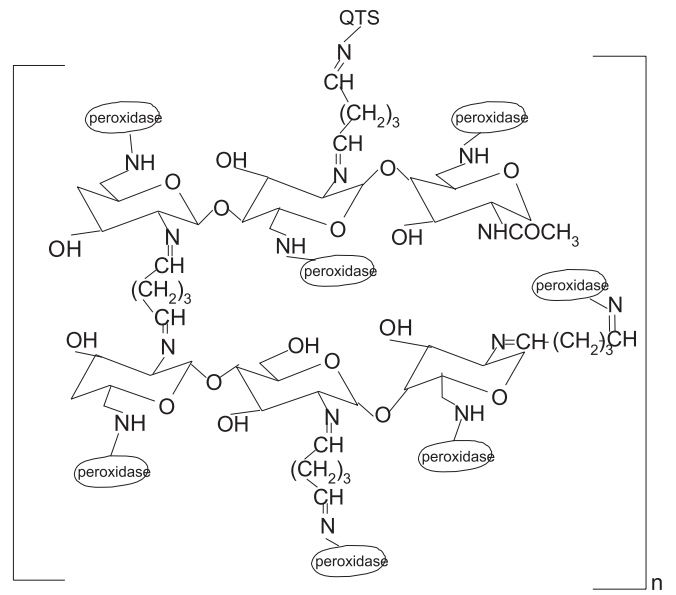

(e)

Figura 2. Esquema da reação entre quitosana (QTS), glutaraldeído, carbodiimida e enzima peroxidase (procedimento II)

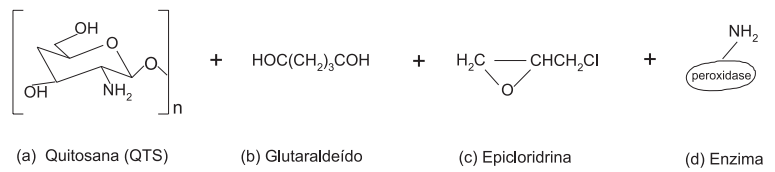

$\begin{array}{llll}\text { (a) Quitosana (QTS) } & \text { (b) Glutaraldeido } & \text { (c) Epicloridrina } & \text { (d) Enzima }\end{array}$

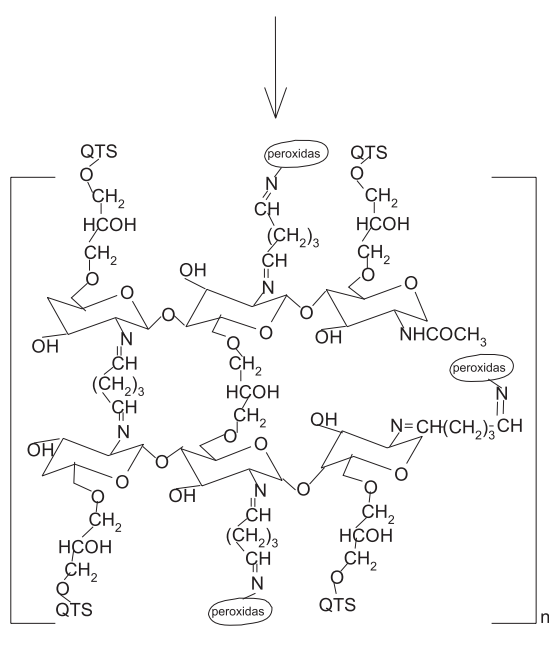

Figura 3. Esquema da reação entre quitosana (QTS), glutaraldeído, epicloridrina e enzima peroxidase (procedimento III)

\section{Otimização da resposta dos biossensores}

Os biossensores de pasta de carbono modificados com a enzima peroxidase incorporada na matriz da quitosana, previamente reticulada e ativada, foram otimizados investigando-se os efeitos da concentração da enzima, $\mathrm{pH}$, freqüência, amplitude de potencial e 
Epc (potencial do pico catódico). A Tabela 1 mostra os parâmetros investigados e as melhores condições obtidas para os biossensores.

Tabela 1. Parâmetros de otimização dos biossensores

\begin{tabular}{lcc}
\hline Parâmetros & Faixa estudada & Melhor resposta \\
\hline Concentração da enzima* & $260-3000$ & 1500 \\
Concentração da enzima** & $0,56-6,0$ & 3,2 \\
$\mathrm{pH}$ & $5,0-9,0$ & 7,0 \\
Freqüência $(\mathrm{Hz})$ & $50-300$ & 100 \\
Amplitude $(\mathrm{mV})$ & $10-200$ & 100 \\
$\mathrm{E}_{\mathrm{pc}}(\mathrm{V}) * * *$ & $+0,45 \mathrm{a}-0,45$ & $-0,2$ \\
$\mathrm{E}_{\mathrm{pc}}(\mathrm{V}) * * * *$ & $+0,3 \mathrm{a}-0,6$ & $-0,2$ \\
\hline
\end{tabular}

*unidade de peroxidase $\mathrm{mg}^{-1}$ de proteína; **unidade $\mathrm{mg}^{-1}$ de pasta de carbono; ***voltametria cíclica; $* * * *$ voltametria de onda quadrada.

Em estudos realizados anteriormente ${ }^{24,35}$ verificou-se que a melhor resposta do biossensor foi obtida na composição de 75/15/ $10 \%(\mathrm{~m} / \mathrm{m})$ de grafite/Nujol/enzima e peróxido de hidrogênio $2,0 \times 10^{-3} \mathrm{~mol} \mathrm{~L}^{-1}$. Portanto, essa composição de pasta de carbono foi selecionada para a construção dos biossensores e as medidas foram obtidas nessa concentração de peróxido de hidrogênio.

O efeito da concentração da enzima sobre a resposta dos biossensores foi estudado na faixa de 260 a 3000 unidades de peroxidase $\mathrm{mg}^{-1}$ de proteína $\left(0,56\right.$ a 6,0 unidades de peroxidase $\mathrm{mg}^{-1}$ de pasta de carbono) imobilizada em pó de quitosana $10 \%(\mathrm{~m} / \mathrm{m})$, previamente reticulada e ativada em $75: 15 \%(\mathrm{~m} / \mathrm{m})$ de grafite/Nujol. Os sinais analíticos (correntes de pico catódico) em solução de hidroquinona $3,0 \times 10^{-4} \mathrm{~mol} \mathrm{~L}^{-1}$ e peróxido de hidrogênio $2,0 \times 10^{-3} \mathrm{~mol} \mathrm{~L}^{-1}$ aumentaram até a concentração de 1500 unidades $\mathrm{mg}^{-1}$ de proteína (3,2 unidades de peroxidase $\mathrm{mg}^{-1}$ de pasta de carbono), mantendose constante em concentrações superiores. Foi selecionada, então, a concentração 1500 unidades $\mathrm{mg}^{-1}$ de proteína para construção dos biossensores.

$\mathrm{O}$ pH exerce grande influência sobre as reações enzimáticas. Foi estudado o efeito do $\mathrm{pH}$ de 5,0 a 9,0 sobre a resposta dos biossensores em solução de hidroquinona $3,0 \times 10^{-4} \mathrm{~mol} \mathrm{~L}^{-1} \mathrm{e}$ peróxido de hidrogênio $2,0 \times 10^{-3} \mathrm{~mol} \mathrm{~L}^{-1}$. A melhor resposta dos biossensores foi verificada em $\mathrm{pH} 7,0$, conseqüentemente, os estudos foram realizados em tampão fosfato $0,1 \mathrm{~mol} \mathrm{~L}^{-1}, \mathrm{pH} \mathrm{7,0}$.

$\mathrm{O}$ parâmetro equivalente à velocidade de varredura da voltametria de onda quadrada é a frequiência de aplicação dos pulsos, (f). A otimização desse parâmetro é de fundamental importância, pois para a maioria dos processos eletródicos, a corrente de pico é diretamente proporcional ao seu valor. Assim, com a maximização do valor de $f$, aumenta-se, conseqüentemente, a sensibilidade da técnica ${ }^{43}$. O efeito de $f$ foi estudado em intervalo de 50 a $300 \mathrm{~Hz}$

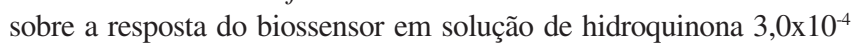
mol L $\mathrm{L}^{-1}$, peróxido de hidrogênio $2,0 \times 10^{-3} \mathrm{~mol} \mathrm{~L}^{-1} \mathrm{em}$ tampão fosfato

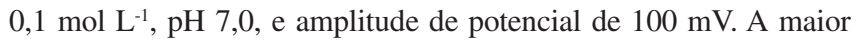
resposta analítica do biossensor foi obtida em $100 \mathrm{~Hz}$. Essa frequiência foi, então, selecionada para os estudos posteriores. Outro parâmetro importante a ser otimizado nessa técnica é a amplitude do pulso de potencial aplicado, $a$. O efeito da variação desse parâmetro foi estudado em uma faixa de 10 a $200 \mathrm{mV}$. O maior sinal foi obtido em $100 \mathrm{mV}$ usando solução de hidroquinona $3,0 \times 10^{-4} \mathrm{~mol}$ $\mathrm{L}^{-1}$, peróxido de hidrogênio $2,0 \times 10^{-3} \mathrm{~mol} \mathrm{~L}^{-1}$ e frequiência $100 \mathrm{~Hz}$.

Neste trabalho, as medidas de voltametria cíclica foram realizadas em uma faixa de potencial de $+0,45 \mathrm{a}-0,45 \mathrm{~V} v s$ eletrodo de $\mathrm{Ag} / \mathrm{AgCl}\left(\mathrm{KCl} \mathrm{3,0} \mathrm{mol} \mathrm{L}^{-1}\right)$ para uma velocidade de varredura de $100 \mathrm{mV} \mathrm{s}^{-1}$.

\section{Voltametria cíclica}

A Figura 4 mostra os voltamogramas cíclicos obtidos com os biossensores contendo extrato bruto de jiló como fonte da enzima peroxidase, imobilizada na matriz da quitosana, usando os três procedimentos diferentes: (I) grupos amino reticulados com glutaraldeído; (II) grupos amino reticulados com glutaraldeído e grupos hidroxila ativados com carbodiimidae, (III) grupos amino reticulados com glutaraldeído e grupos hidroxila reticulados com epicloridrina em solução de hidroquinona $3,0 \times 10^{-4} \mathrm{~mol} \mathrm{~L}^{-1} \mathrm{e}$ peróxido de hidrogênio $2,0 \times 10^{-3} \mathrm{~mol} \mathrm{~L}^{-1}$, em tampão fosfato 0,1 mol L-1, pH 7,0.

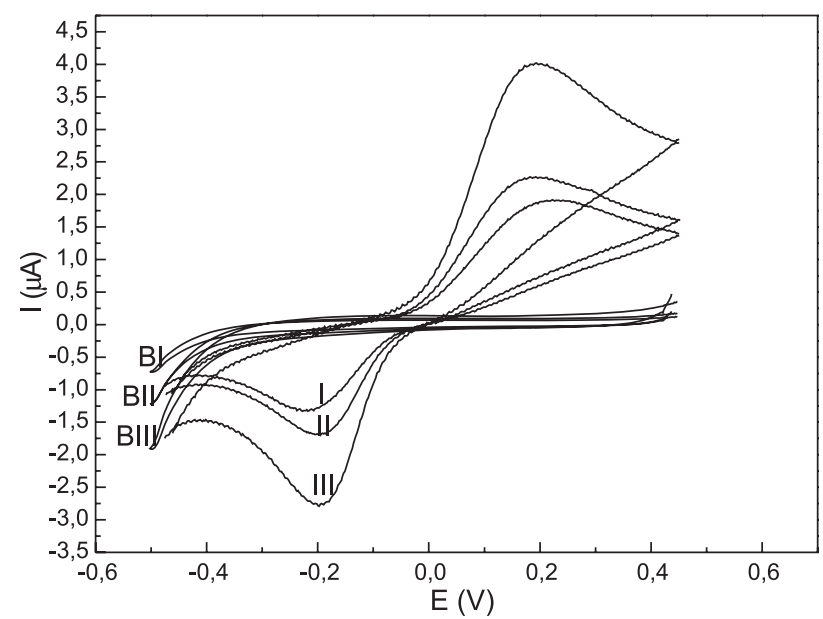

Figura 4. Voltamogramas cíclicos obtidos usando os biossensores. (BI, BII e BIII) solução tampão fosfato 0,1 mol $\mathrm{L}^{-1}, \mathrm{pH} 7,0$, peróxido de hidrogênio

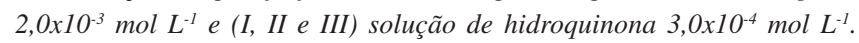
Velocidade de varredura de $100 \mathrm{mv} \mathrm{s}^{-1}$

A enzima peroxidase catalisa a oxidação da hidroquinona para quinona em presença de peróxido de hidrogênio e, posteriormente, a quinona formada é reduzida eletroquimicamente na superfície do biossensor, em potencial de - 0,2 V, como ilustrado na Figura 4. No biossensor (I) a enzima peroxidase foi imobilizada na quitosana reticulada com glutaraldeído, sendo que o menor sinal de corrente de pico catódico, Ipc, foi observado nesse eletrodo. O melhor procedimento para imobilização da peroxidase foi obtido usando a quitosana reticulada com glutaraldeído e epicloridrina, como mostra a Figura 4, voltamograma (III), que apresentou o maior sinal de Ipc. O melhor desempenho do biossensor (III) pode ser devido à formação mais efetiva da rede tridimensional polimérica, onde a enzima pode estar confinada (aprisionada, ocluída) entre os espaços intersticiais das ligações covalentes formadas e ainda ligada nas extremidades do glutaraldeído. Sendo assim, o melhor desempenho dos biossensores propostos neste trabalho está na ordem: biossensor (III) $>$ biossensor (II) $>$ biossensor (I).

\section{Voltametria de onda quadrada}

Neste trabalho, as medidas voltamétricas de onda quadrada, usando os eletrodos de pasta de carbono modificados com a enzima peroxidase foram investigadas no intervalo de potencial de $+0,3$ a - 0,6 V com amplitude de $100 \mathrm{mV}$, freqüência de $100 \mathrm{~Hz}$ e pH 7,0, como apresentado na Tabela 1. A Figura 5 mostra os voltamogramas de onda quadrada obtidos na redução eletroquímica da quinona na superfície dos biossensores (I), (II) e (III). As curvas analíticas para o biossensor (I) ( $\mathrm{Ipc}=1,445+1,538 \times 10^{4}$ [hidroquinona]; $\left.\mathrm{r}=0,9998\right)$, 
biossensor (II) (Ipc=4,219 +2,903x $10^{4}[$ hidroquinona];r=0,9998) e biossensor (III) (Ipc=1,937 + 3,505 x104 [hidroquinona]; $r=0,9994)$, foram construídas a partir das correntes de pico catódicas (Ipc), medidas em potencial de aproximadamente $-0,2 \mathrm{~V}$ em função da concentração de hidroquinona. A Figura 6 mostra a relação linear entre as correntes catódicas e as concentrações de hidroquinona no intervalo de $2,5 \times 10^{-4}$ a $4,5 \times 10^{-3} \mathrm{~mol} \mathrm{~L}^{-1}$ (mostrados na Figura 5), e limite de detecção de $2,0 \times 10^{-6} \mathrm{~mol} \mathrm{~L}^{-1}$.
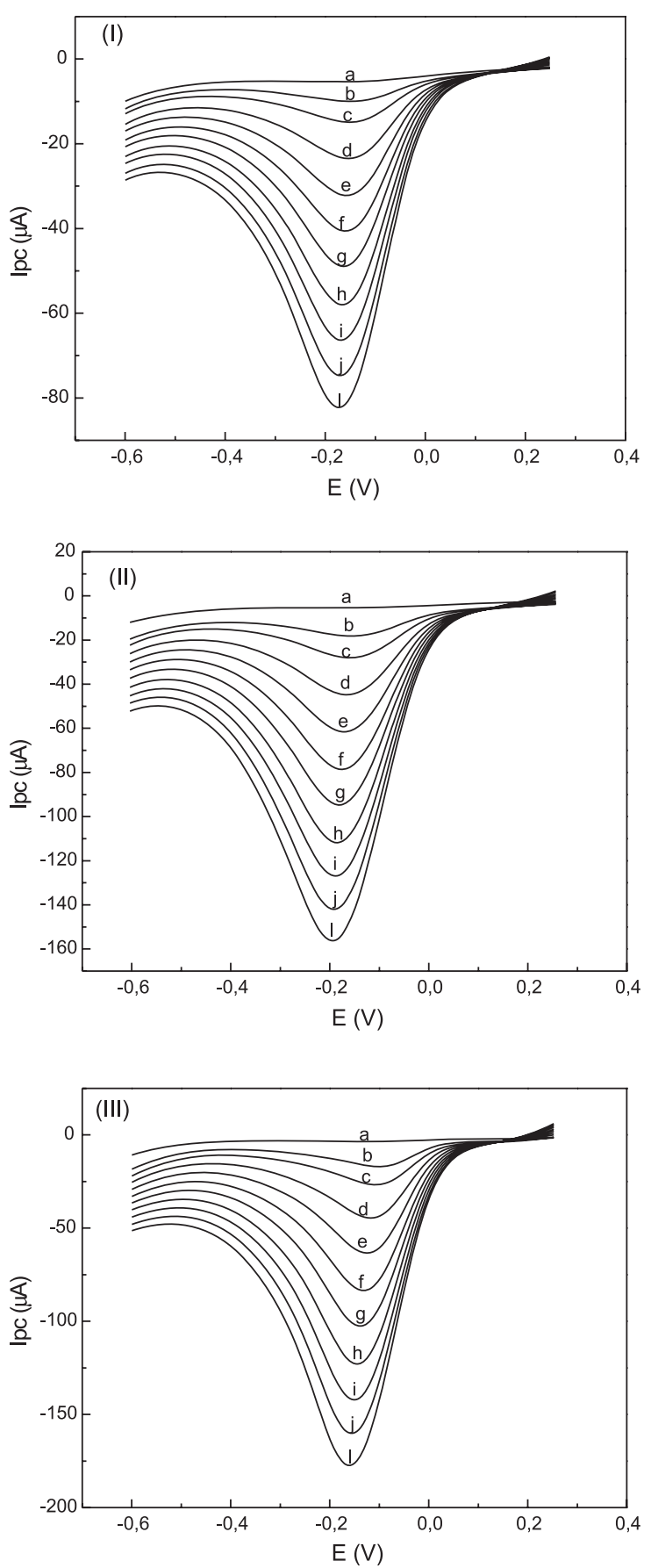

Figura 5. Voltamogramas de onda quadrada obtidos utilizando os biossensores (I), (II) e (III). (a) solução tampão fosfato 0,1 mol $\mathrm{L}^{-1}, \mathrm{pH}$ 7,0, solução de peróxido de hidrogênio $2,0 \times 10^{-3} \mathrm{~mol} \mathrm{~L}^{-1}$ e soluçães de hidroquinona

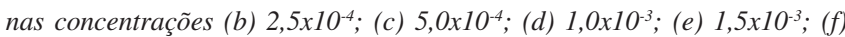
$2,0 \times 10^{-3}$; (g) $2,5 \times 10^{-3}$; (h) $3,0 \times 10^{-3}$; (i) $3,5 \times 10^{-3}$; (j) $4,0 \times 10^{-3}$; (l) $4,5 \times 10^{-3} \mathrm{~mol}$ $\mathrm{L}^{-1}$; amplitude de $100 \mathrm{mV} \mathrm{s}^{-1}$ e freqüência de $100 \mathrm{~Hz}$

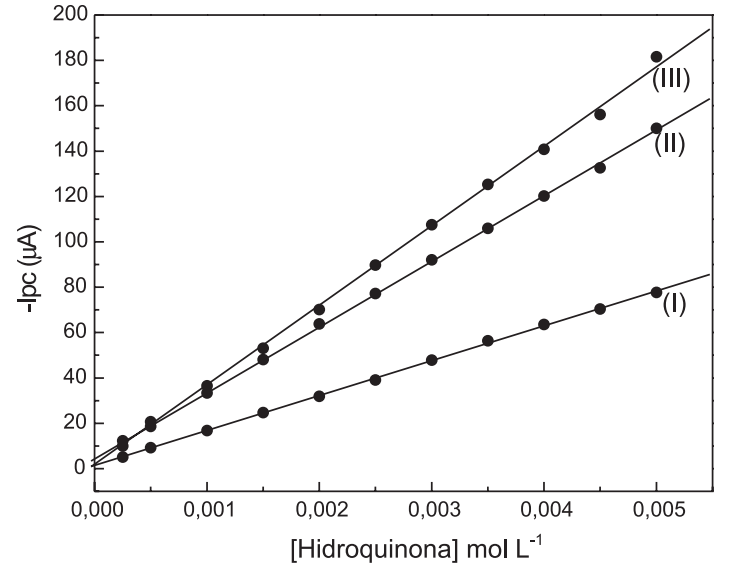

Figura 6. Curvas analíticas para hidroquinona obtidas com os biossensores propostos usando voltametria de onda quadrada

Seletividade, repetibilidade, reprodutibilidade e estabilidade dos biossensores

O efeito de substâncias concomitantes, freqüentemente encontradas em amostras de águas de processos de raios-X, como carbonato de sódio, EDTA, ácido bórico e brometo de potássio foi investigado utilizando os biossensores propostos. Nenhuma dessas substâncias interferiu na resposta dos biossensores, comprovando a ausência de interferência desses compostos. No entanto, amostras de águas obtidas no processo de revelação fotográfica ${ }^{24}$ possuem, além, das substâncias acima que não causam interferência, metol e sulfito que são interferentes em potencial. $\mathrm{O}$ procedimento utilizado para eliminar a presença do metol e sulfito nas amostras investigadas foi o descrito na literatura ${ }^{35}$. Inicialmente, as amostras foram percoladas por uma coluna de vidro de $8,0 \mathrm{~mm}$ (d.i) $\mathrm{x}$ $150 \mathrm{~mm}$ (c) empacotada com resina trocadora fortemente ácida onde todo o metol presente foi retido. Em seguida, em cada amostra foi adicionada solução de formaldeído e a formação do aduto $\alpha$-hidroximetassulfonato, a partir da relação molar de sulfito e formaldeído 1:20, eliminou a interferência dessa substância.

$\mathrm{O}$ estudo da repetibilidade foi feito utilizando os biossensores e 8 medidas sucessivas foram obtidas em solução de hidroquinona $3,0 \times 10^{-4} \mathrm{~mol} \mathrm{~L}^{-1}$ e peróxido de hidrogênio $2,0 \times 10^{-3} \mathrm{~mol} \mathrm{~L}^{-1}$, em tampão fosfato $0,1 \mathrm{~mol} \mathrm{~L}^{-1}$, pH 7,0. O desvio padrão relativo encontrado foi menor que $1,0 \%$ para os biossensores construídos.

$\mathrm{O}$ estudo de reprodutibilidade foi feito, empregando 5 biossensores construídos para os três tipos de procedimentos de imobilização da peroxidase e mesmas condições experimentais. As medidas foram obtidas em triplicata para os biossensores construídos em solução de hidroquinona $3,0 \times 10^{-4} \mathrm{~mol} \mathrm{~L}^{-1}$ e peróxido de hidrogênio $2,0 \times 10^{-3} \mathrm{~mol}$ $\mathrm{L}^{-1} \mathrm{em}$ tampão fosfato $0,1 \mathrm{~mol} \mathrm{~L}^{-1}, \mathrm{pH} 7,0$. O desvio padrão relativo encontrado foi de 3,2\% para os biossensores propostos.

Os biossensores foram estocados à temperatura ambiente e a estabilidade investigada freqüentemente em um período de 180 dias, com medidas realizadas em solução de hidroquinona $3,0 \times 10^{-4} \mathrm{~mol}$ $\mathrm{L}^{-1}$ e peróxido hidrogênio $2,0 \times 10^{-3} \mathrm{~mol} \mathrm{~L}^{-1}$. Não foi observada nenhuma alteração no desempenho dos biossensores. Esta boa estabilidade pode ser atribuída à forte interação entre a enzima peroxidade e a matriz da quitosana ativada e reticulada.

\section{Estudo de recuperação e determinação de hidroquinona}

Os resultados obtidos no estudo de adição e recuperação de hidroquinona em amostras de águas oriundas dos processos de reve- 
Tabela 2. Estudo de adição e recuperação de hidroquinona em água de processo de revelação fotográfica e de raios-X

\begin{tabular}{|c|c|c|c|c|c|c|c|}
\hline \multirow[b]{3}{*}{ Amostra } & \multirow[b]{3}{*}{ Adicionado } & \multicolumn{3}{|c|}{ Hidroquinona $\left(\mathrm{mg} \mathrm{mL}^{-1}\right)$} & & & \\
\hline & & & Biossensores & & \multicolumn{3}{|c|}{ Recuperado (\%) } \\
\hline & & (I) & (II) & (III) & (I) & (II) & (III) \\
\hline \multirow[t]{3}{*}{ A } & 83,3 & $83,0 \pm 0,05$ & $83,2 \pm 0,03$ & $83,1 \pm 0,04$ & 99,6 & 99,9 & 99,8 \\
\hline & 162 & $159 \pm 0,06$ & $164 \pm 0,03$ & $160 \pm 0,03$ & 98,1 & 101 & 98,8 \\
\hline & 195 & $192 \pm 0,07$ & $190 \pm 0,05$ & $197 \pm 0,03$ & 98,5 & 97,4 & 101 \\
\hline \multirow[t]{3}{*}{ B } & 88,3 & $84,0 \pm 0,05$ & $86,4 \pm 0,03$ & $87,2 \pm 0,02$ & 95,1 & 97,8 & 98,7 \\
\hline & 162 & $170 \pm 0,04$ & $165 \pm 0,02$ & $160 \pm 0,07$ & 105 & 99,4 & 102 \\
\hline & 195 & $190 \pm 0,04$ & $193 \pm 0,06$ & $201 \pm 0,06$ & 97,4 & 99,0 & 103 \\
\hline
\end{tabular}

$\mathrm{A}=$ água de processo de revelação fotográfica, $\mathrm{B}=$ água de processo de raios- $\mathrm{X},{ }^{*} \mathrm{n}=6$

Tabela 3. Determinação de hidroquinona em água de processo de revelação fotográfica e de raios-X

\begin{tabular}{|c|c|c|c|c|c|c|c|}
\hline \multirow[b]{3}{*}{ Amostra } & \multirow{3}{*}{$\begin{array}{c}\text { Método } \\
\text { comparativo }^{24}\end{array}$} & \multicolumn{3}{|c|}{ Hidroquinona $\left(\mathrm{mg} \mathrm{mL}^{-1}\right)$} & & & \\
\hline & & & Biossensores & & \multicolumn{3}{|c|}{ Erro Relativo(\%) } \\
\hline & & (I) & (II) & (III) & (I) & (II) & (III) \\
\hline A & $28,9 \pm 0,02$ & $28,8 \pm 0,03$ & $27,8 \pm 0,07$ & $29,1 \pm 0,02$ & $-0,35$ & $-3,8$ & $+0,69$ \\
\hline B & $28,6 \pm 0,01$ & $27,9 \pm 0,05$ & $27,2 \pm 0,03$ & $28,3 \pm 0,01$ & $-2,4$ & $-4,9$ & $-1,0$ \\
\hline $\mathrm{C}$ & $33,0 \pm 0,03$ & $32,6 \pm 0,08$ & $31,4 \pm 0,03$ & $32,9 \pm 0,03$ & $-1,2$ & $-4,8$ & $-0,30$ \\
\hline $\mathrm{D}$ & $32,9 \pm 0,05$ & $30,9 \pm 0,03$ & $33,0 \pm 0,08$ & $31,7 \pm 0,05$ & $-6,1$ & $+0,30$ & $-3,6$ \\
\hline
\end{tabular}

$\mathrm{A}, \mathrm{B}=$ água de processo de revelação fotográfica, $\mathrm{C}, \mathrm{D}=$ água de processo de raios-X, $* \mathrm{n}=6$, nível de confiança $95 \%$

lação fotográfica e raios-X, utilizando voltametria de onda quadrada e os biossensores propostos, estão listados na Tabela 2. Neste estudo foram adicionadas em cada amostra 83,3, 162 e $195 \mathrm{mg} \mathrm{L}^{-1}$ de solução de hidroquinona padrão, seguidas da determinação deste composto e cálculo da porcentagem de recuperação. Os valores de recuperação de hidroquinona variaram de $95,1-105 \%$ para o biossensor (I), 97,8-101\% para biossensor (II) e 98,8-103\% para o biossensor (III). Os resultados obtidos indicam que os procedimentos analíticos propostos não sofrem interferências das matrizes dessas amostras.

Para avaliar o bom desempenho dos biossensores, determinouse a concentração de hidroquinona em água obtida do processo de revelação fotográfica e de raios-X utilizando voltametria de onda quadrada. A Tabela 3 apresenta uma comparação entre a determinação de hidroquinona obtida pelos biossensores propostos e o método comparativo ${ }^{24}$. Os teores de hidroquinona encontrados utilizando os procedimentos propostos estão em concordância com a metodologia padrão, a um nível de confiança de $95 \%$ e dentro do intervalo de erro aceitável.

\section{CONCLUSÃO}

A quitosana possui grande percentual de grupos amino disponíveis e, com isso, apresentou, neste trabalho, boa eficiência como suporte para imobilização da peroxidase obtida do vegetal jiló. O bom desempenho desse biopolímero foi obtido a partir da reticulação com glutaraldeído, epicloridrina e ativação com carbodiimida, que permitiu facilidade de construção, alta estabilidade, simplicidade, precisão e baixo custo. No entanto, o biossensor (III) apresentou melhor desempenho, isso pode ser devido à formação mais efetiva da rede tridimensional polimérica entre quitosana, epicloridrina e glutaraldeído, que além da enzima estar ligada nas extremidades do glutaraldeído, está confinada entre os espaços intersticiais das ligações covalentes formadas.

\section{AGRADECIMENTOS}

Ao suporte financeiro do CNPq (Processo no 472169/2004-1), FUNCITEC e a CAPES pela bolsa de doutorado de I. R. Z. W. de Oliveira.

\section{REFERÊNCIAS}

1. Rosatto, S. S.; Freire, R. S.; Durán, N.; Kubota, L. T.; Quim. Nova 2001, $24,77$.

2. Fatibello-Filho, O.; Capelato, M. D.; Quim. Nova 1992, 15, 28

3. Turner, A.P.F.; Karube, I.; Wilson, G.S.; Biosensors: Fundamentals and Applications, Oxford University Press: Oxford, 1988.

4. Carr, P. W.; Bowers, L. D.; Immobilized Enzymes in Analytical and Clinical Chemistry, John Wiley: New York, 1980.

5. Guilbault, G. G.; Suleiman, A. A.; Fatibello-Filho, O.; Nabi Rahni, M. A. Em Bioinstrumentation and Biosensors; Wise, D. L., ed.; Marcel Dekker: New York, 1991.

6. Trevan, M. D.; Immobilized Enzymes: an Introduction and Applications in Biotechnology, John Wiley \& Sons: New York, 1980.

7. Bickerstaff, G. F.; Immobilization of Enzymes and Cells, Humana Press: New Jersey, 1997.

8. Blum, L. J.; Coulet, P. R.; Biosensor Principles and Applications, Marcel Dekker: New York, 1991.

9. Fatibello-Filho, O.; Vieira, I. C.; Quim. Nova 2002, 25, 455.

10. Krajewska, B.; Enzyme Microb. Technol. 2004, 35, 126.

11. Adams, R. N.; Anal. Chem. 1958, 30, 1576.

12. Gorton, L.; Electroanalysis 1995, 7, 23.

13. Petit, C.; Kauffmann, J. -M.; Anal. Proc. 1995, 32, 11.

14. Kalcher, K.; Kauffmann, J. -M.; Wang, J.; Svancara, I.; Vytras, K.; Neuhold, C.; Yang, Z.; Electroanalysis 1995, 7, 5.

15. Kumar, M.N.V.R.; React. Funct. Polym. 2000, 46, 1

16. Guibal, E.; Sep. Purif. Technol. 2004, 38, 43.

17. Justi, K. C.; Laranjeira, M. C. M.; Neves, A.; Mangrich, A. S.; Fávere, V. T.; Polymer 2004, 45, 6285.

18. Delanoy, G.; Li, Q.; Yu, J.; Int. J. Biol. Macromol. 2005, 35, 89.

19. Magalhães, J. M. C. S.; Machado, A. A. S. C.; Analyst 2002, 127, 1069.

20. Wang, Y.; Zhu, J.; Zhu, R.; Zhu, Z.; Lai, Z.; Chen, Z.; Meas. Sci. Technol. 2003, $14,831$. 
21. Yang, M.; Yang, Y.; Liu, B.; Shen, G.; Yu, R.; Sens. Actuators, B 2004, 101, 269.

22. Jin, Z.; Su, Y. Duan, Y.; Synth. Met. 2001, 122, 237.

23. Bindhu, L. V.; Abraham, E. T.; J. Appl. Polym. Sci. 2003, 88, 1456.

24. Oliveira, I. R. W. Z.; Vieira, I. C.; Lupetti, K. O.; Fatibello-Filho, O.; Fávere, V. T.; Laranjeira, M. C. M.; Anal. Lett. 2004, 15, 3111.

25. Wei, X.; Zhang, M.; Gorski, W.; Anal. Chem. 2003, 27, 2060.

26. Ng, L.T.; Yuan, Y. J.; Zhao, H. J.; Electroanalysis 1998, 10, 1119.

27. Ng, L. T.; Guthrie, J. T.; Yuan, Y. J.; Zha, H. J.; J. Appl. Polym. Sci. 2001, 79, 466.

28. Ruzgas, T.; Csöregi, E.; Emnéus, J.; Gorton, L.; Marko-Vargo, G.; Anal. Chim. Acta 1996, 330, 123.

29. Regalado, C.; Garcia-Almendárez, B. E.; Duarte-Vázquez, M. A.; Phytochem. Rev. 2004, 3, 243.

30. Vieira, I. C.; Fatibello-Filho, O.; Talanta 2000, 52, 681.

31. Fatibello-Filho, O.; Lupetti, K. O.; Vieira, I. C.; Talanta 2001, 55, 685.

32. Vieira, I. C.; Lupetti, K. O.; Fatibello-Filho, O.; Anal. Lett. 2002, 35, 2221.
33. Leite, O. D.; Lupetti, K. O.; Fatibello-Filho, O.; Vieira, I, C.; Barbosa, A. M.; Talanta 2003, 59, 889.

34. Lupetti, K. O.; Vieira, I. C.; Fatibello-Filho, O.; Anal. Lett. 2004, 37, 1833.

35. Vieira, C. I.; Fatibello-Filho, O.; Angnes, L.; Anal. Chim. Acta 1999, 398, 145 .

36. Lee, B. L.; Ong, H. Y.; Shi, C. Y.; Ong, C. N.; J. Chromatogr-Biomed. Appl. 1993, 619, 259.

37. Sakodinskaya, I. K.; Desiderio, C.; Nardi, A.; Fanali, S.; J. Cromatogr. 1992, 596, 95.

38. Firth, J.; Rix, I.; Analyst 1986, 111, 129

39. Wang, L. H.; Analyst 1995, 120, 2241.

40. Gornall, A. G.; Bardawill, C. J.; David, M. M.; J. Biol. Chem. 1949, 177, 751.

41. Roberts, G. A. F.; Chitin Chemistry, The Macmillan Press: New York, 1992.

42. Brugnerotto, J.; Lizardi, J.; Goycoolea, F.M.; Argüelles-Monal, W.; Desbriéres, J.; Rinaudo, M.; Polymer 2001, 42, 3569.

43. Oliveira, R. T. S.; Machado, S. A. S.; Quim. Nova 2004, 27, 911. 